\title{
A Theoretical Framework of Social Responsibility-Internal Control in Chinese Companies
}

\author{
Wei Zhang \\ Accounting Department, Hunan University of Finance and Economics, Changsha, China \\ Email: 125027546@qq.com
}

Received 3 August 2015; accepted 30 August 2015; published 2 September 2015

Copyright (C) 2015 by author and Scientific Research Publishing Inc. This work is licensed under the Creative Commons Attribution International License (CC BY). http://creativecommons.org/licenses/by/4.0/ (c) (i) Open Access

\begin{abstract}
A perfect social responsibility (SR) internal control system is the basis for a company to sustain its long-term development. An integrated framework of SR internal control could be built in three divisions: one is the five key elements of internal control, the other is the major context of SR according to ISO26000: 2010 and "Internal Control Supporting Guidelines", and another is the performing levels which can be categorized as the strategic management level and the operation activities level. A detail analysis of this integrated SR internal control framework was made and suggestions for improving the current SR performing effect were provided.
\end{abstract}

\section{Keywords}

Social Responsibility, Internal Control, Framework, Suggestions

\section{Introduction}

Companies' social responsibility (SR) has become the focus of the public's attention again since various kinds of accidents which are caused by the absence of SR internal control in companies in recent years. It's reported that some juice producers used rotten fruit as raw materials, and contaminated pork, rice, milk powder could be in supermarkets sometimes in China [1]. The lacking of SR has lead to many serious social problems. According to ISO26000: 2010 which provided guidance on social responsibility, SR points to “An organization apply transparent ethical norms of behavior on its decisions or activities and take responsibilities for the social and environment impact”, the "Enterprise Internal Control Supporting Guidelines” (2010) in our country suggested the SRs of companies should be practiced from safety in production, products quality, environment protection, staff rights protection, resource saving, to employment promotion, and etc. [2]. We focus on building a theoretical 
framework for companies in our country, so as to give them specific guidelines to carry out social responsibilities in their operation.

\section{The Integrated Framework of Social Responsibility-Internal Control}

According to the theory of stakeholders, there are many people depend on the company's public information to make their investment or capital collecting decisions. To carry out their SR, companies should make a balance among various kinds of stakeholders so as to support sustainable growth. The internal control of SR aims at building a set of warning and protecting mechanism which can predict the potential operational risks and give an alarm before things go to bad. ISO26000: 2010 summarized SRs as seven aspects which including organization governance, human rights, labor practice, environment protection, fair operating practices, consumer issues, community participation and development, "Enterprise Internal Control Supporting Guidelines” No. 4 includes the SR for production safety, product quality, environment protection, saving resources, promoting employment, protection of the rights and interests of staff [3]. Based on the stakeholder theory and combine the scope of SR defied by ISO26000: 2010 and No. 4 of the "Enterprise internal control supporting guidelines", at the same time, we take the reality of our country into account, we can induce the scope of company's SRs, it could include the safety production, product quality, promoting employment, staff rights, fair operation, community responsibility, the environment protection, resource saving.

There are five key elements of internal control, namely, control environment, risk assessment, information and communication, control activities, supervision system according to report of Committee of Sponsoring Organization, to build the SR internal control; we could use these five elements for reference. The objective of this internal control framework is to facilitate companies to carry out their SRs in their daily operation as well as strategic decisions [4]. On the daily operation level, internal control can be performed through the whole process of procurement, production, marketing activities and so on; on the strategic management level, it can be performed in some substantial decisions, and secure the major decisions be made on the basis of complying with social norms and really taking the SRs into account. The integrated theoretic framework of company's SR internal control can be seen in the Figure 1. To facilitate our analysis, we merged respectively the "promote employment" and "staff's rights", the "environmental protection" and "resource saving". Therefore, the theoretic framework of SR internal control can be built in three divisions as Figure 1 shown.

\section{The Specific Content of Social Responsibility Internal Control in Companies}

The objective of company's SR internal control is to secure all activities in the process of operation can be done on the consideration of SRs. We elaborate the details of actions from two levels including the strategic management level and the operation level.

\subsection{Performing Social Responsibility on the Level of Strategic Management}

On the strategic management level, company should set up the whole internal control framework on the basis of facilitating performing SRs, this objective can be achieved through the following measurements: Firstly, form-

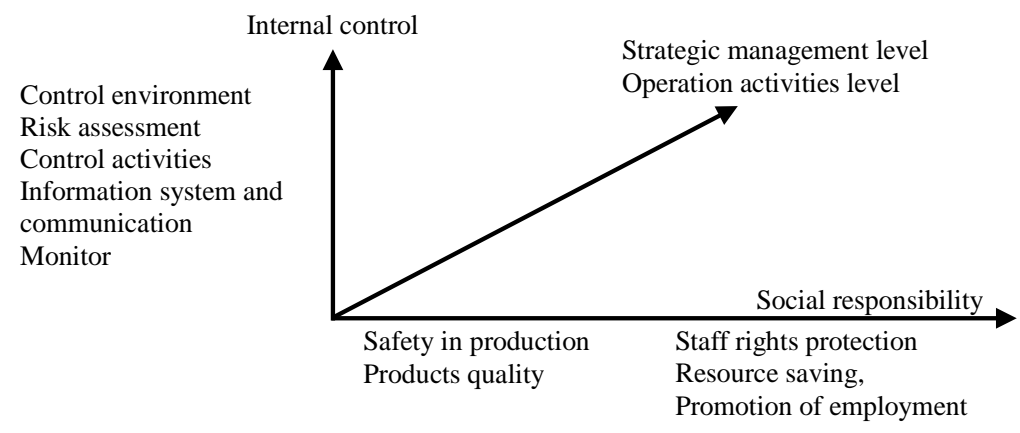

Figure 1. The integrated framework of social Responsibility internal control of companies in China. 
ing a control environment which is beneficial for performing SRs, the values of top management should balance among stakeholders; all important decisions should be made following the basic SR norms, Specialized institution or specialist of social responsibility should be set up and in charge of the governance of the internal control of safety in production, products quality, environment protection, staff rights protection, resource saving, promotion of employment. Secondly, SR should be taken into consideration when companies formulate procedures and policies of control activities, risk assessment, monitoring activities and develop information system, it's necessary for companies to build risk assessment system of the six aspects of SRs.

\subsection{Performing Social Responsibility on the Level of Operation}

\subsubsection{Control Environment}

To build control environment which keeps stressing SR on the operation level, some key control points on the operation level should be considered, to be specific, companies should sponsor programs to train staff at different positions with safety, environment protection awareness, and make promotion based on the overall performances of staff, which include rating the actions they carry out their SRs. In addition, a SRs undertaking culture should be encouraged in the whole process of production and all activities of the company [5].

\subsubsection{Risk Assessment}

Risk assessment on the operation level is to identify, assess and manage risks in the operation process that affect the companies to achieve its SR. For safety production, risk assessment should consider the investments on safety production, safety education and training, safety production emergency management mechanism, staff's access to safety production and etc. For products quality, risk assessment should pay attention to R \& D activities, the eligible status of products, the products recall situation, product quality emergency management; For promoting employment and staff's right protection, personal information and privacy protection, staff compensation, occupational disease prevention and cure, staff training, helping needy workers should be taken into account; For fair operation, assessment should be done to judge whether the business operated honestly; For community responsibilities, we can assess whether companies have brought positive influence to the community; For environment protection and resource saving, the appraise indicator could involve Environmental accident emergency response mechanism, investment on environment protection, energy conservation measures, environment protection actions for every segment of their operation.

\subsubsection{Control Activities}

Control activities on the operation level points to help ensuring companies fulfill the SR of instructions and to implement policies and procedures. The major control activities include performance appraisals, information processing, physical control, separation of duties, authorization and other related activities in safety production, product quality, promoting staff and their rights protection, fair operation, community responsibility, environment protection and resource saving respectively. Performance appraisal should be done regularly, information processing related to every SR should include general control and application control; physical control means the attaching of some important positions should be inhibited; some positions should be separated from others, for example, safety management, internal audit are independent from other duties respectively. Procurement, product, sales should be independent from one another.

\subsubsection{Information System and Communication}

Information system and communication is related to SR information disclosure, including records generating, treatment and report. To build a sound information system and facilitate communication, companies should build internal responsibility system of safety production, product quality, promoting staff and their rights protection, fair operation, community responsibility, environment protection and resource saving, at the same time, communication system of emergency treatment is also needed.

\subsubsection{Monitoring}

Monitoring on the operation level requires companies to make evaluation of the effectiveness of SR internal control, including the design and operation of it, and the corrective action they have taken. Monitor should be sustainable, periodically as well as occasionally, and involve all the six aspects of SR. 


\section{Suggestions for Building a Framework of SR Internal Control in Companies}

A perfect SR internal control system is a basic element for company to sustain its long-term develop, there are at least three suggestions for companies now to promote their SR internal control.

First, regulations on publication of companies' SR information as well as the related internal control should be laid down as soon as possible. Now the listed companies are required to report their internal control report annually, the publication of internal control information is compulsive, but there are no specific guidelines upon the publication of SR internal control, it could be mandated by the regulations due to the reason that the assuming of SR would be beneficial not only for companies’ sustainable development as well as for the welfare of people.

Second, management level in the company should encourage a SR-oriented company culture. The fulfilling of SR is affected by the company culture greatly. Only the management level has realized SC was the endogenous factor of sustainable development, could the company take overall consideration of SC from the daily operational activities to making strategic decisions.

Third, staff should aware that the SR internal control is an integral part of the whole internal control, if any piece of this integrated internal control system turns to be biased, the whole system may fail. For example, if the safe facilities don't work well due to the negligence of staff, then accident may happen, so the whole internal control will be crashed. Therefore, only every staff in different positions has been serious with every tiny piece of the whole system, could the internal control system be secured working effectively.

\section{Conclusion}

To conclude, to build a sound SR internal control system in every company, we should combine all the efforts of the legislation authority, the management level and staff in companies.

\section{Fund}

This paper is the preliminary achievement of the program-“A study on the carbon auditing of enterprises based on the environment property” funded by Hunan University of Finance and Economics.

\section{References}

[1] Wang, J.C. and Shen, X.Q. (2012) Corporate Social Responsibility and Internal Control: Interactive Relationship and Optimization Path Research. Communication of Finance and Accounting, 3, $13-17$.

[2] Wang, H.B. and Liu, S. (2015) A Study on the Internal Control Framework Construction of Corporate Strategic Social Responsibility. Modern Economic Management, 37, 31-37.

[3] Chang, Y. (2013) Probing the Corporate Social Responsibility Internal Control. Journal of Accounting, 6, $113-114$.

[4] Qi, P. and Shang, Y. (2015) A Study on the Internal Control Based on the Corporate Social Responsibility. Enterprise Economy, 4, 45-48.

[5] Financial Reporting Council (2005) Internal Control-Revised Guidance for Directors on the Combined Code. 